\title{
Uphill or Downhill Cross-Country Skiing Presentation of an Easy Applicable Performance Protocol for Youngsters
}

\author{
Benedikt Gasser* \\ Swiss Health \& Performance Lab, Institute of Anatomy, University of Bern, Switzerland
}

Submission: January 02, 2018; Published: January 11, 2018

*Corresponding author: Benedikt Gasser, Swiss Health \& Performance Lab, Institute of Anatomy, University of Bern, Switzerland, Tel: +41316318468; Fax: +413163138 07; Email: gasser@pyl.unibe.ch

\begin{abstract}
Cross-country skiing consists of different performance relevant components. In this study we aimed to analyze downhill and uphill skills in a sample of young cross-country skier in order to compare them to each other to provide training recommendations accordingly and to make recommendations for an easy applicable performance diagnostic protocol in cross-country skiing for young sportsmen. Therefore, twelve cross-country skiers absolved two performance tests: an exhausting uphill course as well as the same course downhill. Course times, maximum and average heart rates, blood lactate concentration, BORG-Scale (6-20) were measured uphill respectively downhill. Interestingly a close relationship between body weight and downhill course time was detected $\left(\mathrm{R}^{2}=0.754\right)$ pointing out relevance of this parameter. Athletes now can position themselves within the sample as good uphill or downhill skier and analyzes allow cross-country skier to position himself as good uphill or downhill skier. When detected weaknesses in downhill skiing eccentric muscle activity could be specifically trained e.g. due some days with alpine skiing. When identifying deficits in downhill skiing cardiovascular system should be prioritized, which even in young athletes could be done with a high-intensity training block?
\end{abstract}

Keywords: Performance capacity; Cross-country skiing; Recreational sports; High-intensity Training

\section{Introduction}

Cross-country skiing has become more popular and popular. From a way of moving having its origin over 4000 years in hunters and mountain men in the north a challenging, highly technically sports form has developed [1-6]. Besides the performance sector the sports also has an enormous development in recreational area and prevention representing the increased demand for this form of exercising [3]. Luckily despite the large number of sportsmen participating injury risk can be taxed as small $[7,8]$. Trying to circumscribe physical requirements for recreational sportsmen especially cardio vascular system is to mention. In the area of the performance oriented recreational sportsmen especially the technical component becomes crucial pinpointing the interaction of endurance and technical component. Depending on performance level in good recreational sport area with the respective equipment faster and more effective techniques can be used with higher rhythm pinpointing the relevance of the interaction of endurance and technical factors [1]. When trying to define the general performance capacity of a cross-country skier maximum oxygen consumption can be mentioned $\left(\mathrm{VO}_{2}\right.$ max $)$ pinpointing relevance of cardiopulmonary system and functional capacity of skeletal muscle [9]. Without doubts the relevance of technique and therefore of coordinative and proprioceptive skills together with cardiopulmonary system seems to be crucial for the physical performance [9].

Therefore, the longer the race distance e.g. $50 \mathrm{~km}$ versus Sprint the more relevant-above threshold-can be exercised [9]. Physiological capabilities in cross-country skiing underlie classical restriction of endurance sports and can be compared for example with marathon or half-marathon running [10]. For example substrate mobilization from fat respectively loaded glycogen reserves can be mentioned as limiting parameter [1012]. Necessity of training specify implies hints that cardiovascular system depending from intensity of exercising adapts accordingly (e.g. in runners different cardiac adaptions than in rowers $[13,14]$. Trying to combine the different components of a good recreational cross-country skier to analyze in detail, different characteristics can be mentioned. A first approximation deliver anthropometric reasons, except in steep uphill parts, heavier cross-country skier seem to have an advantage [15]. The aspect of relevance of anthropometric factors for short versus long 
distance races yielded to a drift whereby cross-country skier focusing on sprint distance had a higher BMI [16].

To sum up the performance determining factors result from the high muscular whole body usage of upper and lower extremity with a resulting high uptake of oxygen $\left(\mathrm{VO}_{2}\right.$ max $)$ combined with the ability to tolerate high lactazid concentrations in skeletal muscle [3-6,17-19]. Therefore hints can be deciphered that the technical and sport motoric development in cross-country skiing increases relevance of upper body for moving forward respectively hints exist that performance is mainly determined by the strength of upper body $[7,12,20]$. Besides the relevance of cardio pulmonic system proprioception and equilibrium has to be mentioned. Especially equilibrium is for example for downhill skiing respectively gliding abilities especially with the new material of high relevance. With the new material even by recreational sportsmen in downhill speed of over $50 \mathrm{~km} / \mathrm{h}$ can be achieved, in performance oriented cross-country skiers speed from 60 till $80 \mathrm{~km} / \mathrm{h}$ and even more in well-prepared tracks are not seldom [7].

Especially downhill parts are signed by further requirements of skeletal muscle system and especially eccentric muscle contraction becomes more important $[21,22]$. Eccentric muscle contraction is necessary for breaking or stooping a movement or when energy is absorbed or while breaking or absorbing energy in downhill skiing. In cross-country skiing the eccentric muscle activity is crucial whereby especially activity of $\mathrm{M}$. quadriceps femoris becomes important and becomes a crucial performance determining factor [21-26]. The above mentioned reveals that cross-country skiing besides the without doubts important cardiopulmonary component is signed by further biological elements of equilibrium and the ability of eccentric muscle activity. The combination of these factors determines performance capacity of a cross-country skier. Besides the initially mentioned measurement of $\mathrm{VO}_{2}$ max more possibilities of quantifying relevant factors [27]. What is generally missed is a simple an easy applicable performance diagnostic protocol allowing in an easy applicable manner to conduct a performance diagnostic with young cross-country skier respectively young skiers to sensible them for the thematic. This yields to the aim of this study to analyze different performance determining factors in a sample of young cross-country skiers concerning interaction of different parameters allowing relevant recommendations for individual training.

\section{Material and Methods}

\section{Participants}

Twelve youth cross-country skier $(12.4 \pm 2.1$ years, $48.6 \pm$ $14.3 \mathrm{~kg}, 161 \pm 8.3 \mathrm{~cm}$ ) with regular cross-country skiing activity and good recreational level. Participants were informed and consent for study was obtained. Participants were advised to be rested, under normal nutrition. All participants absolved uphill and downhill skiing parts.

\section{Field measurements and Equipment}

Field measurements consisted of an exhaustive crosscountry course uphill as well as downhill. Participants were advised to go to their performance limit. Measurements took place on the course Salwideli (Luzern/Entlebuch/Switzerland) (Figure 1) on around 1350 meter altitudes, which has to be considered when comparing measured values with other studies $[25,28,29]$. Course of ascent and descent were the same and distance was around 500 meters, difference in altitude was about 60 meter. Lactate values of uphill and downhill courses were measured immediately after arrival. Between ascent and descent participants had to rest till a rest breathe frequency (about 20 breathes per minute) were achieved. This yielded to a break of around 2 minutes for the majority of the sample aiming to simulate a situation of a difficult ascent with relatively shortly following of a descent. Measurements of Lactate were always conducted immediately after arrival with Lactate One/Axonlab/ Aarau/Switzerland with capillary blood sample from ear and BORG-Scale (6-20) was applied [30]. Heart rate was measured with Polar Heart Rate gear (R300/Polar/Zug/Schweiz). All measurements were made in good weather condition and temperature around 0 degrees.

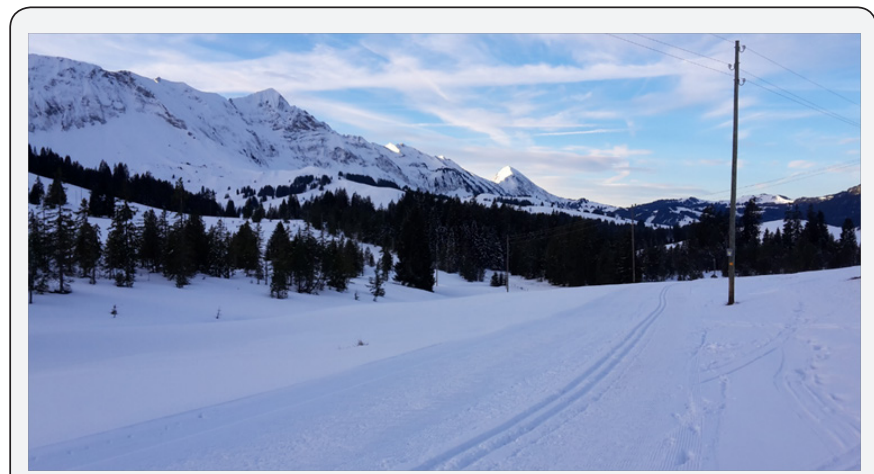

Figure 1: The area the study was conducted (Salwideli/ Entlebuch/Switzerland).

\section{Statistical procedures}

For course times uphill and downhill mean and standard deviations of lactate, maximum and average heart rate and BORG-Scale (6-20) were calculated [31]. For analyzing relationship between courses times of uphill and downhill a linear regression as well as coefficient of determination were calculated. Furthermore, coefficient of determination between courses times uphill and downhill of ascent and body weight. Data were analyzed with SPSS (IBM, USA) and Excel (Microsoft, USA).

\section{Results}

Table 1 shows the different values of course times uphill and downhill, heart rate max as well as average, lactate and BORGScale (6-20). It has to be considered, that relatively high values of lactate concentration of more than $10 \mathrm{mmol} / \mathrm{l}$ were measured. Figure 2 shows the different course times. Skiers below the 
mean (horizontal line) have to be taxed as over average in uphill course respectively downhill course. Figure 3 shows the linear regression of course times uphill (x-Axis) versus downhill (y-axis) implying the slower someone was uphill the faster the skier is downhill $\left(\mathrm{R}^{2}=0.7082\right)$. If searching for reasons for good uphill skiers versus good downhill skiers beside the intuitive reason of fatigue after ascent body weight can be mentioned. The calculated relationship between body weight and downhill time revealed an astonishingly high coefficient of determination of $\mathrm{R}^{2}=0.754$, which correlates with other findings and points out relevance of body weight $[15,16]$.

Table 1: Mean and standard deviation of uphill and downhill courses $(n=12)$.

\begin{tabular}{|c|c|c|c|c|c|}
\hline & Time & $\begin{array}{c}\text { Heart } \\
\text { Rate }\end{array}$ & $\begin{array}{c}\text { Heart } \\
\text { Rate }\end{array}$ & $\begin{array}{c}\text { Lactate } \\
(\mathbf{m m o l} / \mathbf{l})\end{array}$ & $\begin{array}{c}\text { BORG- } \\
\text { Scale } \\
\mathbf{( 6 - 2 0 )}\end{array}$ \\
\cline { 3 - 6 } & & $\begin{array}{c}\text { Max } \\
\text { (Beats/ } \\
\text { min) }\end{array}$ & $\begin{array}{c}\text { Average } \\
\text { (Beats/ } \\
\text { min) }\end{array}$ & & \\
\hline \multirow{2}{*}{ uphill } & $\begin{array}{c}191.0 \pm \\
29.1\end{array}$ & $\begin{array}{c}187.2 \pm \\
7.4\end{array}$ & $\begin{array}{c}162.2 \pm \\
6.7\end{array}$ & $10.4 \pm 4.1$ & $18.7 \pm 0.4$ \\
\hline \multirow{2}{*}{ downhill } & $48.4 \pm$ & $165.6 \pm$ & $139.2 \pm$ & $10.0 \pm 2.5$ & $12.0 \pm 3.2$ \\
\hline
\end{tabular}

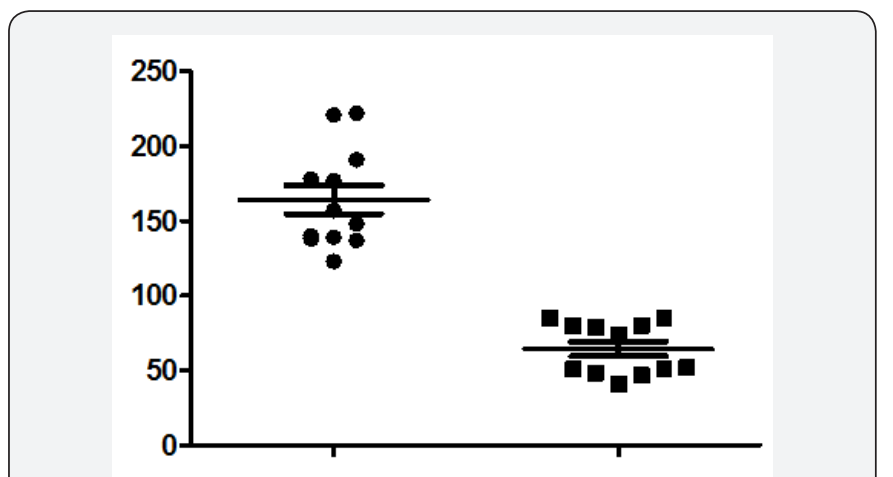

Figure 2: Average courses times of uphill and downhill. Mean and standard deviation are given $(n=12)$.

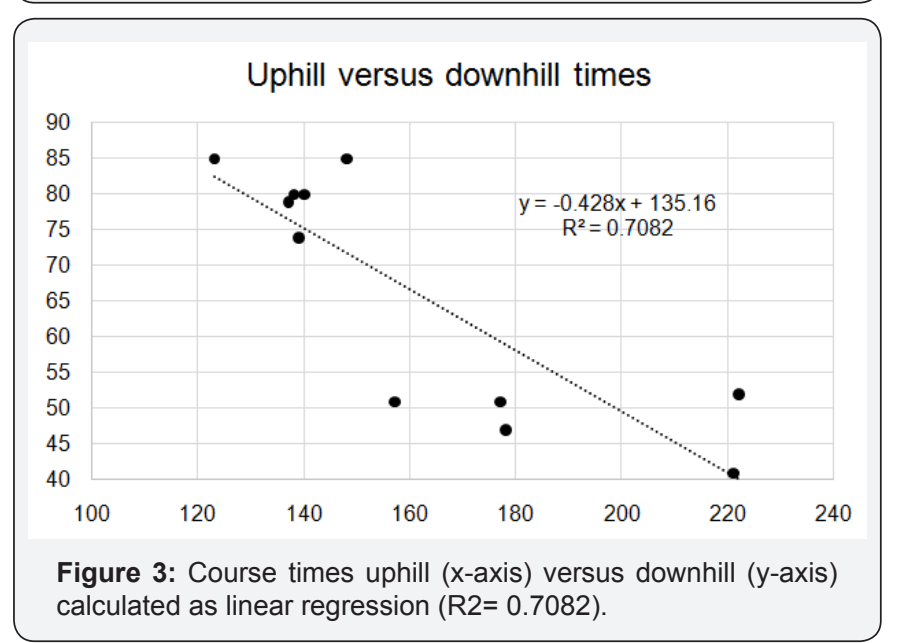

Hereby it is to mention that body weight is not a sharp parameter and should not be used solely e.g. for measurements of lean mass seems to be as parameter for performance diagnostic more accurate [32]. Concerning rate of perceived exertion it can be mentioned, that the correlative relationship between heart rate and BORG-Scale (6-20) in ascent was 0.51 war and was reduced to 0.02 while descent. Between BORG-Scale (6-20) and Lactate in ascent -0.11 as well as in descent 0.31 , whereby these relationships have to be taxed as small due to measurements of very high validity of BORG-Scale (6-20) [33]. This might be due to the fact that skiers went to their performance limit with maximum exertion reducing analyzed range (E.g. standard deviation of BORG-Scale uphill 0.4).

\section{Discussion}

The aim of this study was to develop an easy and applicable performance protocol for young recreational cross-country skiers, which allow them to conduct a performance diagnostic in an easy manner. Therefore, twelve cross-country skiers absolved an uphill and downhill course till exhaustion with immediately following of measurements of lactate, heart rate and BORG-Scale (6-20). These two field tests allow now the young athlete to position itself as more good in uphill versus downhill skiing (Figures $2 \& 3$ ). Both tests were absolved till exhaustion, which is in accordance with the high average blood lactate concentration of $10 \mathrm{mmol} / \mathrm{l}$ (Table 1). Thereby it's to mention that the high detected concentration of blood lactate concentrations producing muscular fatigue does also have a protective effect on muscle [34]. Pedersen, Nielsen [35] could show that Lactate has a positive effect on performance of a tired muscle while influencing activity of Cl--channels, which are essential for action potentials [35].

Combing back to the performance protocol respectively field tests. Especially foryoung athletes, trainers have with this method a possibility to detect juniors willing to go to their performance borders. These athletes should be carefully observed keeping in mind negative effects for example of overtraining. Furthermore, for this sample it can be mentioned, that the better in ascent the slower in descent. Reasons for these results can be detected in the high lactate concentrations (in some athletes up to 15 mmol/l after ascent, reducing downhill skiing abilities while descent implying that in the break between ascent and descent a complete reduction into lactate rest states of $2 \mathrm{mmol} / \mathrm{l}$ was not possible. Furthermore, the finding that heavier cross-country skiers were faster in downhill can be well connected with newer findings, whereby sprint cross-country skiers were heavier than on long courses $(10,15,30,50 \mathrm{~km}$ races) [16,32]. Muscular usage is different (force versus endurance) and different requirements on organ systems evoke consequently.

Even in the here conducted protocol descent was characterized through a short time of exercise compared to ascent. Furthermore, also for physical reasons - performing a huge amount of kinetic energy [1/2 mass $(\mathrm{kg}) \mathrm{x}$ velocity ${ }^{2}(\mathrm{~m} /$ $\mathrm{sec})]$ is necessary to be transformed into potential energy while 
ascent [mass $(\mathrm{kg}) \mathrm{x}$ gravity constant $\left(\mathrm{m} / \mathrm{sec}^{2}\right) \mathrm{x}$ height $\left.(\mathrm{m})\right]$. To summarize, the aim of this study was to analyze the relationship of different performance determining elements in cross-country skiing. Figures $2 \& 3$ allow now a cross-country skier to position itself in the sample. If deficits exist in the important ascent abilities, cardio-pulmonary system should be trained. If deficits in the important downhill abilities are detected especially eccentric muscle activity should be trained. To simplify, ascent stimulates cardio-pulmonary system while descent stimulates downhill skills.

It has to be considered, that participants were advised to ascent as fast as possible but no technical restrictions were made (classic versus skating V1 or V2). It can be mentioned, that when using proper technique no difference in oxygen consumption in skating sub techniques V1 versus V2 could be detected [36,37]. Other studies reveal that ascent is of major importance implying relevance to train cardiovascular system constantly [18]. Even in youngsters a High-intensity Training block could improve performance capacity substantially [38]. Willing to quantify descent requirements, it can be mentioned from alpine skiing (Super G, giant slalom, Slalom) a dominance of eccentric muscle activity, which could be trained by some alpine training days $[23,39]$.

\section{Practical Implications}

a) The here presented protocol allows skiers to position itself as good ascent or descent cross-country skier.

b) This allows secondary to make individual training recommendations in the way that good cross-country skier with deficits in downhill or ascent should specifically train deficits in order to improve total performance.

c) When deficits in the important ascent abilities can be detected it is recommended to specifically train the cardiovascular system. Even in young cross-country skier this can be done with a high-intensity training block.

\section{Acknowledgment}

Special thanks go to Hans-Martin Henny for his support and critical thinking.

\section{References}

1. Gilli G (1992) Skating-Eine Technik entwickelt sich weiter. Läufer, Switzerland 9(1): 24-25.

2. Clifford PS (1992) Scientific basis of competitive cross-country skiing. Medicine and Science in Sports and Exercise 24(9): 1007-1009.

3. Babiel S (2002) Feldstudie zu biomechanischen Einflussgrössen in ausgewählten Skilanglauf-Techniken. Dissertation, Universität Bochum.

4. Schwirtz A (2006) DSV-Lehrplan Skilanglauf. Technik-MethodikTraining. Deutscher Skiverband, Germany.

5. Niebling V (2013) Skilanglauf. Praxiswissen vom Profi: Klassisch und Skating. München: Bruckmann Verlag.
6. Bläse D, Egger T, Hölig W, Leicht S, Paternoster F, et al. (2013) Offizieller DSV-Lehrplan Skilanglauf: Technik-Unterrichten-Praxis. Stuttgart, Pietsch, Germany.

7. Renstrom P, Johnson RJ (1989) Cross-country skiing injuries and biomechanics. Sports Med 8(6): 346-370.

8. Hintermann B (1990) Korrektur der Fußstatik-aber wie/Belastungen des Bewegungsapparats im Skilanglauf (3). Läufer, Switzerland 7(10): $52-53$

9. Larsson P, Olofsson P, Jakobsson E, Burlin L, Henriksson Larsén K (2002) Physiological predictors of performance in cross-country skiing from treadmill tests in male and female subjects. Scand J Med Sci Sports 12(6): 347-353.

10. Coso JD, Salinero JJ, Lara B, Abián Vicén J, Gallo Salazar C, et al. (2017) A comparison of the physiological demands imposed by competing in a half-marathon vs a marathon. J Sports Med Phys Fitness 57(11): 13991406.

11. Knechtle B, Bircher S (2006) Limitierende Faktoren der Fettverbrennung. Schweizerische Zeitschrift für Sportmedizin und Sporttraumatologie 54(2): 51-56.

12. Mahood NV, Kenefick RW, Kertzer R, Quinn TJ (2001) Physiological determinants of cross-country ski racing performance. Med Sci Sports Exerc 33(8): 1379-1384.

13. Wasfy MM, Weiner RB, Wang F, Berkstresser B, Lewis GD, et al. (2015) Endurance Exercise-Induced Cardiac Remodeling: Not All Sports Are Created Equal. J Am Soc Echocardiogr 28(12): 1434-1440.

14. Gaskill SE, Serfass RC, Bacharach DW, Kelly JM (1999) Responses to training in cross-country skiers. Med Sci Sports Exerc 31(8): 12111217.

15. Bergh U, Forsberg A (1992) Influence of body mass on cross-country ski racing performance. Med Sci Sports Exerc 24(9): 1033-1039.

16. Losnegard T, Hallén J (2014) Physiological differences between sprintand distance-specialized cross-country skiers. Int J Sports Physiol Perform 9(1): 25-31.

17. Sandbakk $\varnothing$, Leirdal S, Ettema G (2014) The physiological and biomechanical differences between double poling and G3 skating in world class cross-country skiers. Eur J Appl Physiol 115(3): 483-487.

18. Sandbakk $\emptyset$, Losnegard T, Skattebo $\emptyset$, Hegge AM, Tønnessen E, et al (2016) Analysis of Classical Time-Trial Performance and TechniqueSpecific Physiological Determinants in Elite Female Cross-Country Skiers. Front Physiol 7: 326.

19. Smith GA (1992) Biomechanical analysis of cross-country skiing techniques. Med Sci Sports Exerc 24(9): 1015-1022.

20. Vandbakk K, Welde B, Kruken AH, Baumgart J, Ettema G, et al. (2017) Effects of upper-body sprint-interval training on strength and endurance capacities in female cross-country skiers. PLoS One 12(2): e0172706.

21. Vogt M, Däpp C, Blatter J, Weisskopf R, Suter G, et al. (2003) Training zur Optimierung der Dosierung exzentrischer Muskelaktivität. Schweizerische Zeitschrift für Sportmedizin und Sporttraumatologie 51(4): 188-191.

22. Vogt M, Hoppeler HH (2014) Eccentric exercise: Mechanisms and effects when used as training regime or training adjunct. J Appl Physiol 116(11): 1446-1454.

23. Berg HE, Eiken 0 (1999) Muscle control in elite alpine skiing. Med Sci Sports Exerc 31(7): 1065-1067.

24. Gross M, Lüthy F, Kroell J, Müller E, Hoppeler H, et al. (2010) Effects of eccentric cycle ergometry in alpine skiers. Int J Sports Med 31(8): $572-576$. 
25. Hoppeler H, Vogt M (2001) Muscle tissue adaptations to hypoxia. J Exp Biol 204(18): 3133-3139.

26. Lindstedt SL, LaStayo PC, Reich TE (2001) When active muscles lengthen: properties and consequences of eccentric contractions. News Physiol Sci 16: 256-261.

27. Fasel B, Favre J Chardonnens, J Gremion G, Aminian K (2015) An inertial sensor-based system for spatio-temporal analysis in classic cross-country skiing diagonal technique. Journal of Biomechanics 48(12): 3199-3205

28. Albisser P (1992) Kleine Wetterkunde für Bergsteiger. Bern, SACVerlag.

29. Winkler K, Brehm HP, Haltmeier J (2008) Bergsport Winter. Bern, SACVerlag, Aufl.

30. Borg G (2004) Anstrengungsempfinden und körperliche Aktivität. Deutsches Aerzteblatt 101(15): A-1016.

31. Bortz J (2005) Statistik für Human-und Sozialwissenschaftler Berlin, Springer.

32. Carlsson T, Tonkonogi M, Carlsson M (2016) Aerobic power and lean mass are indicators of competitive sprint performance among elite female cross-country skiers. Open Access J Sports Med 8(7): 153-160.

33. Scherr J, Wolfarth B, Christle JW, Pressler A, Wagenpfeil S, et al (2013) Associations between Borg's rating of perceived exertion and physiological measures of exercise intensity. European Journal of Applied Physiology 113(1): 147-155.

34. Wahl P, Bloch W, Mester J (2009) Moderne Betrachtungsweisen des Laktats: Laktat ein überschätztes und zugleich unterschätztes Molekül. Schweizerische Zeitschrift für «Sportmedizin und Sporttraumatologie» 57(3): 100-107.

35. Pedersen TH, Nielsen OB, Lamb GD, Stephenson DG (2004) Intracellular acidosis enhances the excitability of working muscle. Science 305(5687): 1144-1147.

36. Myklebust H, Losnegard T, Hallén J (2013) Differences in V1 and V2 ski skating techniques described by accelerometers. Scand J Med Sci Sports 24(6): 882-893.

37. Losnegard T, Myklebust H, Hallén J (2012) No differences in 02-cost between V1 and V2 skating techniques during treadmill roller skiing at moderate to steep inclines. J Strength Cond Res 26(5): 1340-1347.

38. Breil F (2010) Block Periodization of high-intensity interval training underlying cardiac, hematological and muscular adaptive mechanisms for the efficient improvement of $\mathrm{VO}_{2}$ max. Dissertation, ETH Zürich.

39. Gilli G (1993) Dynamisches Gleichgewicht im Skilanglauf. Läufer Switzerland, 10(11): 42-43.

\section{Your next submission with Juniper Publishers} will reach you the below assets

- Quality Editorial service

- Swift Peer Review

- Reprints availability

- E-prints Service

- Manuscript Podcast for convenient understanding

- Global attainment for your research

- Manuscript accessibility in different formats

( Pdf, E-pub, Full Text, Audio)

- Unceasing customer service

Track the below URL for one-step submission https://juniperpublishers.com/online-submission.php 